\title{
O perfil socioeconômico e a percepção ambiental dos pescadores da Lagoa do Apodi, Rio Grande do Norte, Brasil
}

\author{
Socio-economic profile and environmental perception of fishers of Lagoa do \\ Apodi, Rio Grande do Norte, Brazil \\ El perfil socioeconómico y la percepción ambiental de los pescadores de Lagoa \\ do Apodi, Rio Grande do Norte, Brasil \\ Jorge Luís de Oliveira Pinto Filho ${ }^{1}$ \\ Samilly Brito Nobre ${ }^{1}$ \\ Manoel Mariano Neto ${ }^{1}$
}

Recebido em 28/02/2019; revisado e aprovado em 30/05/2019; aceito em 13/08/2019

DOI: http://dx.doi.org/10.20435/inter.v21i4.2425

\begin{abstract}
Resumo: A pesca é uma das principais atividades desenvolvidas para garantir a alimentação humana, contribuindo para seu desenvolvimento. Entretanto vem enfrentando dificuldades atualmente especialmente a pesca artesanal, que usa de pouca tecnologia -, além da ganância das grandes corporações pesqueiras. O presente trabalho tem como objetivo descrever a pesca artesanal na Lagoa do Apodi, RN, por meio da descrição do perfil socioeconômico e da percepção ambiental dos pescadores. Como procedimento metodológico, foi realizada uma revisão de literatura; elaboração de questionário semiestruturado, abordando aspectos sobre perfil socioeconômico e percepção ambiental, com aplicação a 52 pescadores, obedecendo ao processo de amostragem de forma aleatória; e tratamento de dados com Microsoft Software Excel 2013. Observou-se que os pescadores apresentam baixa renda e escolaridade, porém esses fatores não influenciaram na percepção ambiental dos indivíduos. Os impactos positivos da atividade pesqueira na lagoa relacionam-se com a geração de renda, a geração de empregos e a produção de alimentos. Evidenciou-se que os pescadores têm consciência dos impactos negativos decorrentes da atividade, como a pesca predatória, que leva à escassez de peixes e até mesmo à alteração da qualidade hídrica. Os principais conflitos para os pescadores relacionam-se com a pesca predatória, a disputa de terra entre pescadores e agricultores e o processo de urbanização com despejo de esgotos. Com os resultados obtidos, detectou-se ausência de políticas públicas que contribuam para o fomento da pesca artesanal voltada ao desenvolvimento local.
\end{abstract}

Palavras-chave: atividades pesqueiras tradicionais; pesca artesanal e desenvolvimento local; conflitos socioeconômicos e ambientais.

Abstract: Fishing is one of the main activities developed to ensure food, contributing to its development. However, currently has faced difficulties - especially the small-scale fishing, which uses low-technology-, in addition to the greed of large fishing corporations. The present work aims to describe the small-scale fishing in the Lagoa do Apodi, RN, through the description of the socio-economic profile and environmental perception of fishers. As a methodological procedure, we performed a literature review; preparation of semi-structured questionnaire, covering aspects of socio-economic profile and environmental perception, applied to 52 fishers, following the random sampling process; and processing of data with Microsoft Excel Software 2013. We observed that the fishers present low income and education; however, these factors did not influence on environmental perception of individuals. The positive impacts of fishing activity in the lagoon are related to income generation, job creation, and food production. We evidenced that the fishers are aware of the negative impacts arising from the activity, such as over-fishing, which leads to scarcity of fish and even to changing water quality. The main conflicts to fishers are relating to predatory fishing, land dispute between fishers and farmers, and with urbanization process with sewage dumping. With the results obtained, we detected an absence of public policies that may contribute to the promotion of small-scale fishing geared to local development.

Keywords: Traditional fishing activities; small-scale fishing and local development; socio-economic and environmental conflicts.

Resumen: La pesca es una de las principales actividades desarrolladas para garantizar la alimentación humana, contribuyendo a su desarrollo. Sin embargo, actualmente se enfrenta a dificultades, especialmente

\footnotetext{
${ }^{1}$ Universidade Federal Rural do Semi-Árido (Ufersa), Pau dos Ferros, Rio Grande do Norte, Brasil.
} 
la pesca artesanal, que utiliza poca tecnología, además de la codicia de las grandes corporaciones pesqueras. El presente trabajo tiene como objetivo describir la pesca artesanal en Lagoa do Apodi, RN, a través de la descripción del perfil socioeconómico y la percepción ambiental de los pescadores. Como procedimiento metodológico, se realizó una revisión de la literatura; preparación de un cuestionario semiestructurado, que aborde aspectos del perfil socioeconómico y la percepción ambiental, con aplicación a 52 pescadores, obedeciendo al proceso de muestreo aleatorio; y el procesamiento de datos con Microsoft Software Excel 2013. Se observó que los pescadores tienen bajos ingresos y escolaridad, pero estos factores no influyeron en la percepción ambiental de los individuos. Los impactos positivos de la actividad pesquera en la laguna están relacionados con la generación de ingresos, la creación de empleo y la producción de alimentos. Se evidó que los pescadores son conscientes de los impactos negativos resultantes de la actividad, como la pesca depredadora, que conduce a la escasez de peces e incluso a cambios en la calidad del agua. Los principales conflictos para los pescadores están relacionados con la pesca depredadora, la disputa de tierras entre pescadores y agricultores y el proceso de urbanización con eliminación de aguas residuales. Con los resultados obtenidos, hubo una falta de políticas públicas que contribuyan a la promoción de la pesca artesanal orientada al desarrollo local.

Palabras claves: actividades de pesca artesanal; pesca artesanal y el desarrollo local; conflictos socioeconómicos y ambientales.

\section{INTRODUÇÃO}

A pesca é tida como uma das principais atividades desenvolvidas para garantir a alimentação humana, criando novas técnicas de captura e explorando ecossistemas aquáticos mediante características dadas por meio da vida dos rios e hábitos dos peixes analisados periodicamente (RAMIRES; BARRELA; ESTEVES, 2012), para os quais, ao longo dos séculos, foi possível o aprimoramento da atividade por meio do conhecimento acumulado em relação ao ciclo de vida das espécies pescadas (DIEGUES, 2004).

Com isso, a pesca artesanal é caracterizada como uma atividade de pouca tecnologia, de pequeno porte e simples, ou sem embarcações, que utiliza a mão de obra familiar, sendo realizada para fins de subsistência, comercialização local e geração de renda.

Dessa forma, a pesca é vista como uma atividade em expansão no Brasil, a qual gera alimentos ricos em proteínas e minerais, imprescindíveis para a saúde humana, e que fortalece a produção do pescado ao mesmo tempo que gera renda para as comunidades locais, apresentando mais de um milhão de pescadores artesanais (MINISTÉRIO DA PESCA E AGRICULTURA [MAPA], 2012).

Mediante tais aspectos de relevância, em 2003, foi criada a Secretaria Especial de Aquicultura e Pesca (Seap) (ORGANIZAÇÃO DAS NAÇÕES UNIDAS PARA ALIMENTAÇÃO E A AGRICULTURA [FAO BRASIL], 2006). Posteriormente, foi instituída a Lei n. 11.959/2009, que dispõe sobre a Política Nacional de Desenvolvimento Sustentável da Aquicultura e da Pesca, a qual regula as atividades pesqueiras no Brasil, definindo-as como toda operação, ação ou ato tendente a extrair, colher, apanhar, apreender ou capturar recursos pesqueiros.

No Nordeste brasileiro, a pesca artesanal permite a segurança alimentar e o sustento de muitas comunidades pesqueiras, já que colabora com aproximadamente $85 \%$ do pescado capturado que vai para comercialização local (SILVA, 2010). Nesse contexto, esta é uma das principais atividades econômicas do estado do Rio Grande do Norte, sendo realizada atualmente a partir de métodos de baixo custo, como embarcações comumente não motorizadas, aparelhagem de pesca diversa e com pouca autonomia (INSTITUTO BRASILEIRO DO MEIO AMBIENTE [IBAMA], 2008), e sendo tradicionalmente desenvolvida no mar, onde se realiza por meio do trabalho manual e em forma de organização coletiva, como colônias de pescadores (SILVA, 2010). 
Ainda é possível identificar a pesca artesanal em águas interioranas, como em rios, lagos, lagoas e barragens. No interior do Rio Grande do Norte (RN), localiza-se o município de Apodi, que faz parte da Bacia do Rio Apodi-Mossoró. Este território teve seu processo de colonização às margens da Lagoa do Apodi, RN, que foi utilizada ao longo dos anos para diversos usos: abastecimento de água, agricultura, pesca, manutenção de fauna e flora, recreação, navegação, diluição de efluentes, uso paisagístico e recarga do aquífero.

Hoje, a pesca artesanal na Lagoa do Apodi, é uma das principais atividades com grande importância para a economia local, pois é fonte de sustento de várias famílias. Entretanto, em virtude dos processos de uso e ocupação dessa lagoa, a pesca vem passando por processos de alterações.

Na linha de compreensão da contribuição da pesca para o desenvolvimento local, a literatura internacional aponta estudos realizados em diversos países, a saber: Vilches e Ríos (2011), Allison et al. (2012), Barakagira e Wit (2017), Ndhlovu et al. (2017) e Mozumder et al. (2018).

Estudos sobre a pesca artesanal e o desenvolvimento local no Brasil apresentaram diferentes abordagens, como em Carvalho e Callou (2008), sobre análise de Projetos de Extensão Pesqueira da Secretaria Especial de Aquicultura e Pesca, da Presidência da República; Cunha e Callou (2013), sobre políticas públicas e capital social para o desenvolvimento local da pesca; Acauan et al. (2018), sobre aspectos legais da pesca artesanal; e Meira e Almeida (2018), sobre os impactos dos projetos de instalações portuárias em comunidades pesqueiras.

A compreensão do desenvolvimento da pesca artesanal se dá ainda com estudos sobre perfil socioeconômico, percepção ambiental e práticas ambientais dos pescadores que vêm sendo realizados por Santos et al. (2011); Seixas et al. (2014); Silva (2014); Silva, Oliveira e Schiavetti (2014); Morais (2016); Zappes, Oliveira e Di Beneditto (2016); e Zacarkim, Dutra e Oliveira (2017). No entanto ainda existem lacunas na caracterização ambiental de pescadores em ambientes de águas doces no semiárido brasileiro.

Portanto este trabalho tem como objetivo geral investigar a pesca artesanal na Lagoa do Apodi, com ênfase na identificação do perfil socioeconômico, na análise de percepção ambiental e no levantamento de práticas ambientais dos pescadores.

O presente artigo está estruturado em introdução, metodologia, resultados e discussão, considerações finais e referências.

\section{METODOLOGIA}

Esta investigação apresenta caráter descritivo, que tem como propósito descrever características de determinada população ou o estabelecimento de relação entre variáveis; e exploratório, o qual tem como finalidade desenvolver, esclarecer e modificar conceitos e ideias (GIL, 2008), analisando os problemas mais precisos dos pescadores da Lagoa do Apodi, RN, por meio de procedimentos metodológico-científicos.

\subsection{Caracterização da Lagoa do Apodi, RN}

Este estudo foi realizado sobre a lagoa presente no bairro Malvinas, da cidade de Apodi, RN, no semiárido nordestino (Figura 1). Ela é localizada a aproximadamente $342 \mathrm{~km}$ da capital potiguar Natal e tem como acesso principal a BR-405, tornando-se fator primordial para o desenvolvimento local (INSTITUTO BRASILEIRO DE GEOGRAFIA E ESTATÍSTICA [IBGE], 2016). 
A Lagoa do Apodi faz parte da Bacia Hidrográfica do Rio Apodi-Mossoró (que apresenta uma superfície equivalente a $26,8 \%$ do território estadual), sendo a extensão desse ambiente de 15 km na margem esquerda do Rio Apodi, dividindo-se entre as fronteiras do Ceará e do Rio Grande do Norte, com capacidade hídrica, em período de cheia, de 20 milhões de $\mathrm{m}^{3}$ de água (EMPRESA DE PESQUISA AGROPECUÁRIA DO RIO GRANDE DO NORTE [EMPARN], 2017).

Figura 1 - Localização da Área de Estudo.

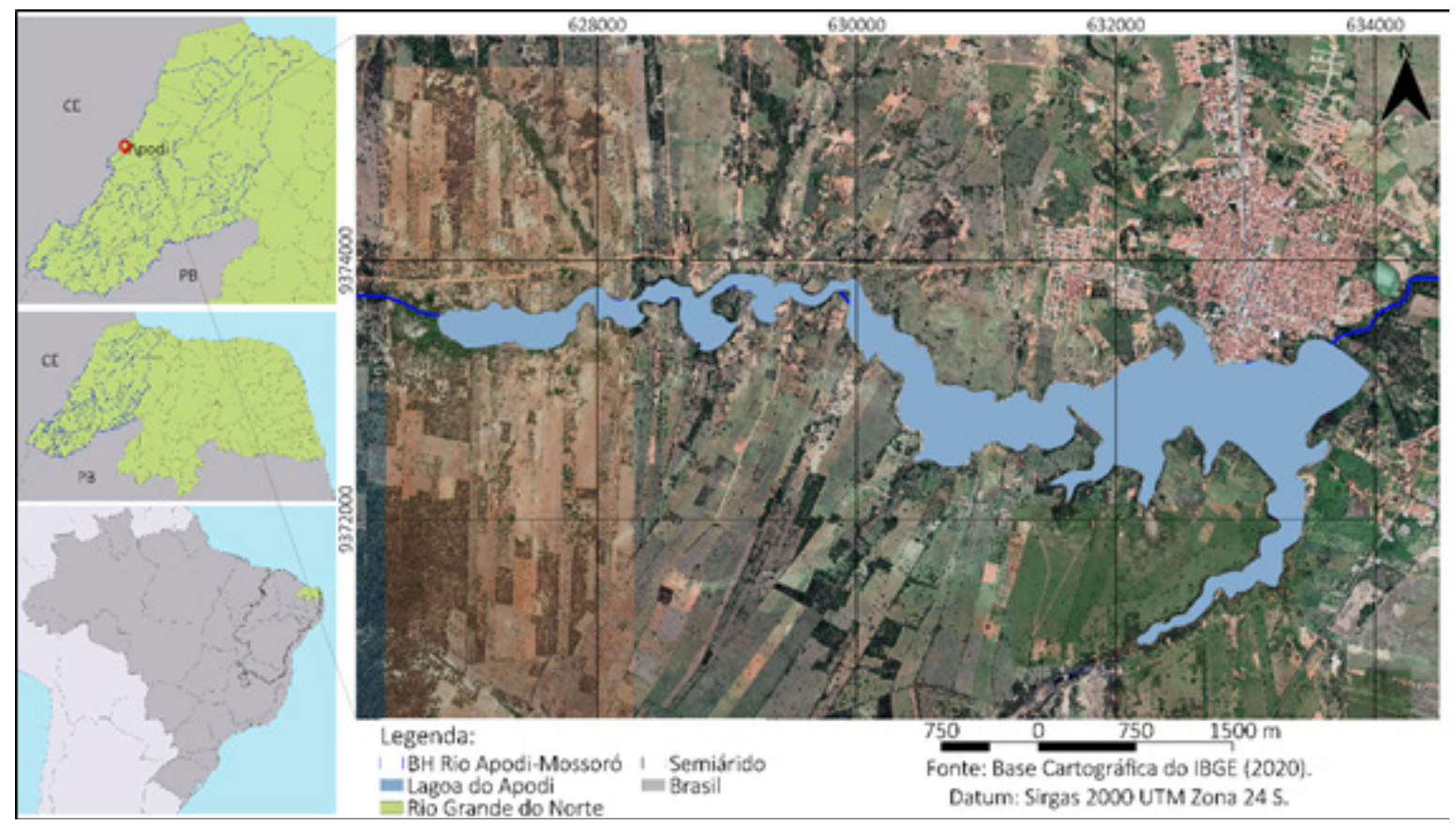

Fonte: Elaborado pelos autores (2020).

Esse ambiente aquático contribui para o desenvolvimento das atividades tradicionais locais (PINTO FILHO; OLIVEIRA, 2008), já que apresenta diversos usos ao longo dos anos, com fortes laços para a agricultura, a pesca e o abastecimento de água para consumo humano no passado, assim como o surgimento do uso com fins recreativo no presente (SOARES et al., 2019), proporcionando processos de degradação devido à ação antrópica com impactos de ordem urbana e agrícola (PINTO FILHO; SANTOS; SOUZA, 2012).

\subsection{Procedimentos metodológicos}

i) Projeto de Pesquisa

Esta pesquisa é resultante do projeto "Estudos ambientais da Lagoa do Apodi-RN: construindo as ciências ambientais", que tem como objetivo conhecer a relação ambiente (Lagoa do Apodi, RN) e sociedade (população de Apodi, RN), estando cadastrado na Pró-Reitoria de Pesquisa e Pós-Graduação (PROPPG) da Universidade Federal Rural do Semi-Árido (Ufersa).

ii) Definição do tema

Empregou-se o tipo de estudo de caso, que se caracteriza por sustentar pesquisas profundas, com um ou poucos objetos, adquirindo conhecimento amplo e detalhado (GIL, 2008), definindo o recorte temático do perfil socioeconômico, a percepção ambiental e as práticas ambientais dos 
pescadores da lagoa, tendo em vista que a pesca é uma das principais atividades econômicas realizadas na lagoa, a qual sofre diretamente com efeitos da poluição no meio, o que provoca uma diminuição da qualidade de trabalho dos indivíduos, gerando potencial de alteração da qualidade e saúde dos peixes da lagoa e uma alerta sobre a população consumidora.

iii) Pesquisa bibliográfica

A natureza das fontes da pesquisa conduziu à adoção de formas que possibilitam a classificação, como: bibliográfica, que oferece ao pesquisador uma gama de fenômenos muito mais ampla em relação àquela que poderia pesquisar diretamente; e documental, que se refere à coleta de informações secundárias e sem tratamento analítico (GIL, 2008). Dessa forma, realizouse uma investigação sistemática acerca dos recursos hídricos, da pesca artesanal e dos conflitos pelo uso e acesso das águas.

iv) Coleta de dados

A pesquisa de campo consiste na investigação empírica realizada no local onde ocorre ou ocorreu um fenômeno ou que dispõe de elementos para explicá-lo (GIL, 2008). Na perspectiva de investigar a pesca artesanal na Lagoa do Apodi, RN, utilizou-se a percepção ambiental, já que é considerada uma ferramenta de sustentabilidade que compreende melhor as inter-relações entre o homem e o ambiente (MELAZO, 2005).

Com isso, utilizou-se como fonte de dados a pesquisa de campo, por meio das técnicas de pesquisa: documento da colônia de pescadores, sobre o quantitativo de pescadores; checklist, ideal para identificar e enumerar os impactos ocorrentes na Lagoa do Apodi, RN, por ser um método rápido e conciso (SÁNCHEZ, 2012); e questionários, pois permitem obter conhecimentos, crenças, sentimentos, valores, interesses, expectativas, aspirações, temores e comportamentos (GIL, 2008). O questionário abordou o perfil socioeconômico, percepção ambiental e práticas ambientais, contendo 36 questões que necessitavam de respostas discursivas e de múltipla escolha.

O procedimento de amostragem ocorreu por método aleatório, com indivíduos que fazem uso da lagoa para pesca. Para isso, levou-se em consideração a informação de que na colônia de pescadores de Apodi, colônia Z-48, existem 405 pescadores cadastrados na Confederação Nacional de Pescadores e Aquicultores (CNPA), dos quais 240 atuam diretamente na lagoa. Dessa forma, foi estabelecida uma amostragem com base em Bolfarine e Bussab (2005), considerando o tamanho da amostra para uma população de 240 ( $N=240)$, com margem de erro de 12\%, confiança de $88 \%$ e variabilidade máxima:

$$
n=\frac{N}{4(N-1)\left(\frac{E}{Z_{\frac{ळ}{2}}}\right)+1}=\frac{240}{4(240-1)\left(\frac{0,12}{1,96}\right)+1}=52
$$

Em que:

$$
\begin{aligned}
& N=\text { tamanho da população; } \\
& Z_{\infty / 2}=\text { é o valor crítico da distribuição de probabilidade normal; } \\
& E=\text { margem de erro. }
\end{aligned}
$$


No primeiro momento, realizou-se um pré-teste com 10\% da amostragem (cinco questionários), com a finalidade de adequar as variáveis, otimizar o tempo e planejar a execução da aplicação do survey. No segundo momento, ocorreu o survey, com aplicação dos questionários, sendo apresentado o Termo de Consentimento Livre e Esclarecido (TCLE). A escolha pelo método de survey deve-se ao fato de permitir enunciados descritivos, explicativos e exploratórios sobre uma população, isto é, descobrir a distribuição de certos traços e atributos com a amostra dessa população (BABBIE, 2001).

A aplicação dos questionários com os pescadores foi realizada às margens da lagoa, na área do bairro Malvinas, no qual, segundo Soares et al. (2019), a maior parte (28,57\%) de seus moradores são pescadores. A aplicação foi realizada em dias distintos, entre os meses de dezembro de 2017 e março de 2018.

v) Tabulação e tratamento dos dados

Este trabalho classifica-se como uma pesquisa mista, que permite a análise de dados qualitativos e quantitativos, trazendo um resultado mais amplo para análise (GIL, 2008). Com isso, a tabulação dos dados foi realizada com auxílio do Microsoft Software Excel 2013, que disponibiliza gráficos comparativos dos resultados, tornando viável a discussão e análise dos dados e a comparação com trabalhos da revisão sistemática.

\section{RESULTADOS E DISCUSSÃO}

\subsection{Perfil socioeconômico dos pescadores artesanais}

A pesca na Lagoa do Apodi, RN, é uma atividade econômica secular, sendo desenvolvida desde o processo inicial de uso e ocupação desse ambiente. Com isso, para melhor compreender a dinâmica dos pescadores locais e conhecer suas condições de vida, faz-se necessário realizar uma investigação do perfil socioeconômico desses indivíduos.

Os indivíduos que praticam a pesca na Lagoa do Apodi, RN, em sua maioria, com 84,62\% dos entrevistados, são do sexo masculino, e 15,38\%, do sexo feminino. Resultados semelhantes também foram encontrados por Morais (2016), o qual observou em seu estudo que $84,5 \%$ dos pescadores da colônia Z-55 do município de Mossoró, RN, eram do sexo masculino. Tal situação merece destaque, já que Hirata e Kergoat (1998) asseguram que, desde os anos 1970, as divisões sexuais do trabalho causam desigualdades quanto ao valor dos trabalhos masculinos e femininos.

O perfil do pescador da Lagoa do Apodi, RN, foi caracterizado quanto à idade com uma variabilidade de 18 anos até mais de 55 anos, em que 5,8\% tinham entre 18 e 25 anos; 15,4\%, de 26 a 35 anos; 23,1\%, de 36 a 45 anos; 32,70\%, de 46 a 55 anos; e 23\%, mais de 55 anos de idade. Resultados similares foram encontrados por Silva (2014), ao afirmar que $41 \%$ dos pescadores do Rio Mumbaba, na Paraíba, tinham idade superior a 50 anos. Esse cenário pode ser atribuído aos novos trabalhos que surgiram na região ao longo dos anos e que vêm sendo ocupados por jovens, ao contrário do interesse por ocupações tradicionais.

O grau de escolaridade dos pescadores, em sua a maioria (67,30\%), é do ensino fundamental incompleto, sendo o restante distribuído em: $11,54 \%$ sem escolaridade formal; 7,69\% com fundamental completo; 9,62\% com médio incompleto; e 3,85\% com médio completo. Resultados parecidos são expostos por Zacarkim, Dutra e Oliveira (2017), os quais mostram que $90 \%$ dos pescadores da foz do Rio Araguaia (entre os estados do Tocantins e do Pará) têm até ensino fundamental completo. As atividades tradicionais não necessitam de instrução formal para sua 
ocupação, proporcionando, na visão de Bourdieu e Passeron (1998), uma desigualdade escolar proveniente das diferentes classes sociais. Esse cenário possibilita a necessidade de adequação de educação ambiental não formal, com base na Política Nacional de Educação Ambiental (BRASIL, 1999).

O limitado índice educacional reflete na renda mensal dos pescadores da Lagoa do Apodi, RN, visto que 94,23\% não ultrapassam de um salário mínimo mensal, seguido de 5,77\% que faturam entre um e dois salários mínimos. Resultados similares são apresentados por Silva, Oliveira e Schiavetti (2014), os quais constataram que $88 \%$ dos pescadores artesanais da Reserva de Desenvolvimento Sustentável Estadual Ponta do Tubarão têm uma renda mensal de até um salário mínimo. Essa baixa renda pode estar relacionada ao fato de 92,30\% desses pescadores terem a pesca como único trabalho, em que, mediante as dificuldades enfrentadas, esse cenário passa a refletir diretamente na renda média. O nível de escolaridade tem uma implicação direta na empregabilidade, ou seja, um aumento no grau de escolaridade poderá derivar em um resultado mais positivo em relação ao emprego do indivíduo (BALASSIANO; SEABRA; LEMOS, 2005).

Evidencia-se, assim, a necessidade de políticas públicas para esse setor, que possibilitem assegurar o desenvolvimento local. Kashimoto, Marinho e Russeff (2002) afirmam que essas políticas públicas precisam ser alheias ao movimento flutuante de sucessões eleitorais, que deem sustentação à ampliação do acesso popular à educação, à saúde, à moradia, mas também à cultura e ao "ócio criativo".

A pesca artesanal possibilita a manutenção da identidade local, que já vem sendo mantida, pois a maioria (75\%) dos pescadores afirmaram que fazem uso da lagoa há mais de 30 anos; 7,69\%, de 20 a 30 anos; 5,77\%, de 10 a 20 anos; 7,69\%, de 6 a 10 anos; e 3,85\%, de 2 a 5 anos. Este resultado é diretamente relacionado ao fato de todos os pescadores entrevistados serem naturais da cidade de Apodi, RN, possibilitando, para Kashimoto, Marinho e Russeff (2002), a formação da identidade cultural que é imprescindível ao fortalecimento da comunidade em seu ambiente, permitindo a escolha das melhores soluções e, consequentemente, a condução do processo de desenvolvimento local, pois Jesus (2003) define esse fenômeno como a mobilização de pessoas e instituições buscando a transformação da economia e da sociedade locais.

A vivência dos pescadores locais é praticamente para a referida atividade, visto que $98,10 \%$ afirmaram ter apenas a pesca como meio econômico, enquanto uma pequena parcela de 1,90\% apontou desenvolver atividades agrícolas. Morais (2016) apresenta resultados similares, em que detectou que 96,9\% dos pescadores do Rio Apodi-Mossoró sobrevivem da pesca de subsistência. Esse cenário de informalidade também se repete com base em Acauan et al. (2018), já que 80\% dos pescadores no município de Penha, SC, trabalham dessa forma. Tal cenário pode ser induzido devido ao baixo grau de escolaridade que proporciona a consolidação de atividades informais.

A pesca na Lagoa do Apodi-RN tem um alcance local, visto que 76,27\% comercializam seus produtos no próprio município e 18,64\% realizam para consumo próprio. Ainda, 3,39\% comercializam na região e 1,70\% vende em outros municípios do RN. Este resultado é semelhante ao de Morais (2016), que em seu estudo no Rio Apodi-Mossoró encontra um percentual de 85,6\% de pescadores que fazem a comercialização diretamente ao consumidor local (venda de porta em porta), devido à maior facilidade para comercialização e à diminuição de gastos. A pesca contribui para o desenvolvimento local, com a criação de novas oportunidades de trabalho e rendimentos (JESUS, 2003), possibilitando a obtenção de meios de ampliação para que a população participe na construção da sociedade (ROCHA; BURSZTYN, 2005). 
A abrangência local dessa atividade é caracterizada pela quantidade diária de pescado, já que 65,38\% dos pescadores capturam diariamente de $1 \mathrm{~kg}$ a $5 \mathrm{~kg}$; 32,70\%, de $5 \mathrm{~kg}$ a $10 \mathrm{~kg}$; e apenas 1,92\%, de $15 \mathrm{~kg}$ a 20 kg, apresentando as espécies mais capturadas: tilápia, tucunaré, traíra e piautrês-pintas. Resultado semelhante é encontrado por Morais (2016), em que no Rio Apodi-Mossoró o peixe mais capturado pelos pescadores é a tilápia, sendo justificado devido à Lagoa do Apodi, RN, estar situada na mesma Bacia Hidrográfica. As características dessa produção configuram-se como como pesca artesanal, que contribuem para o desenvolvimento local (MEIRA; ALMEIDA, 2018).

O desenvolvimento da pesca no ambiente estudado ocorre de forma tradicional, visto que a maioria dos pescadores (86,54\%) afirmam ter aprendido com familiares, enquanto $13,46 \%$ conheceram sozinhos essa técnica. Silva, Oliveira e Schiavetti (2014) mostram resultado semelhante em sua pesquisa na Reserva de Desenvolvimento Sustentável Estadual Ponta do Tubarão, onde observaram que, ao questionar a profissão do pai dos entrevistados, 65\% responderam que também eram pescadores e que se iniciaram na pesca com a influência de gerações anteriores, por meio do pai ou amigos muito próximos. A pesca é uma atividade tradicional, que contribui para o desenvolvimento local, ratificando Rocha e Bursztyn (2005), que visualizam a participação como social, uma precondição básica à obtenção do tão almejado desenvolvimento local sustentável.

Portanto o tempo de exercício desse ofício é um fator determinante para configurar-se como atividade tradicional, como já assinalado em linhas pretéritas. Similaridade é encontrada por Seixas et al. (2014), no qual os pescadores artesanais da Praia da Cocanha, em Caraguatatuba, SP, apresentam tempo médio de atividade de 19 anos.

\subsection{Percepção ambiental dos pescadores artesanais}

Ao reconhecer a pesca como atividade tradicional na Lagoa do Apodi, RN, é necessário compreender a relação dos pescadores com esse ambiente; com isso, a percepção ambiental é a forma adequada, já que permite a representação que uma população tem sobre o seu ambiente (DEL RIO; OLIVEIRA, 1996) e pode ser utilizada como uma forma de averiguar os valores atribuídos a um lugar.

A lagoa apresenta importância imprescindível para a população local, já que 94,23\% a consideram muito importante e 5,77\% a consideram importante. Reforçando esse pensamento, o entrevistado 1 afirma que: "A lagoa é muito importante, pois nos dá o alimento, emprego e renda". Este fato é corroborado por Soares et al. (2019), ao afirmarem que a lagoa apresenta valor para a população local, com base nas formas de sua compreensão, possibilitando a convicção de os indivíduos pertencerem ao ambiente.

Diante da importância da lagoa para a população local, indagou-se como eles avaliam os processos de poluição, sendo evidenciado que $98,10 \%$ afirmaram que existe poluição por atividades urbanas e 1,90\% disse ser por causa de atividades agrícolas. Corroborando esse cenário, o entrevistado 2 aponta que: "Os esgotos da cidade vão para a lagoa". Resultados similares foram determinados por Soares et al. (2019), ao afirmarem que a população do bairro Malvinas, onde se localiza a Lagoa do Apodi, RN, apontou que a principal forma de poluição é a urbana. Os determinados tipos de usos do ambiente podem gerar a poluição ambiental, de origem natural e antrópica (DERISIO, 2012).

Quando investigado especificamente sobre a relação da pesca com a Lagoa do Apodi, RN, observou-se que, para os pescadores locais, essa atividade oportuniza impactos positivos relacionados com a geração de renda (39,35\%) e a geração de empregos (17\%) (Figura 2). Já os 
impactos negativos com destaque foram: pesca predatória (41,56\%), escassez de peixes (14,29\%) e a alteração da qualidade hídrica (14,29\%) (Figura 3). Esses resultados são corroborados por Meira e Almeida (2018) ao investigarem a pesca no litoral sul do Espírito Santo. Dessa forma, para atenuar a referida problemática, Carvalho e Callou (2008) e Cunha e Callou (2013) apontam a necessidade de ações para o empoderamento dos pescadores, contribuindo com o desenvolvimento do capital humano, de forma a possibilitar que esses sujeitos reivindiquem seus direitos.

Figura 2 - Impactos positivos da pesca

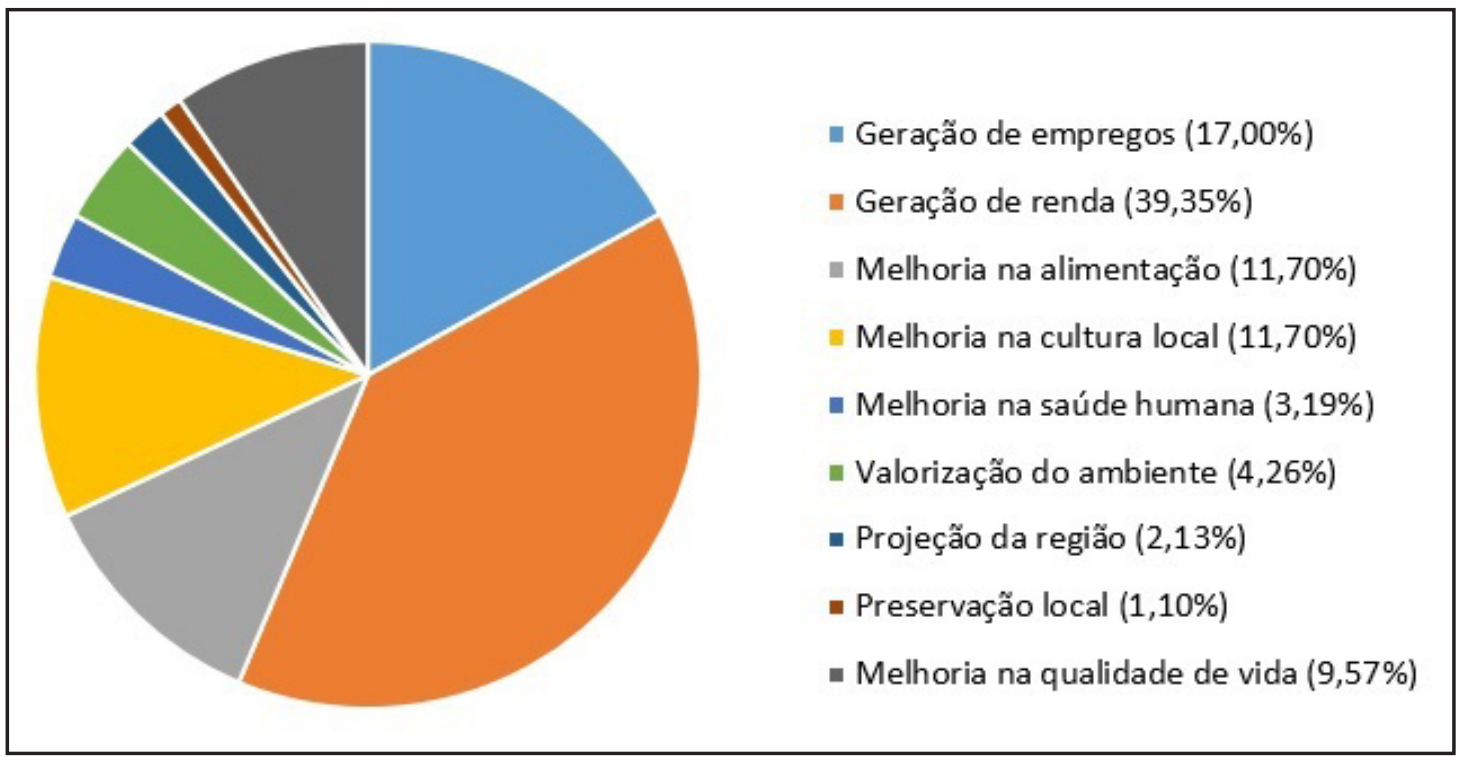

Fonte: Elaborado pelos autores (2020).

Figura 3 - Impactos negativos da pesca

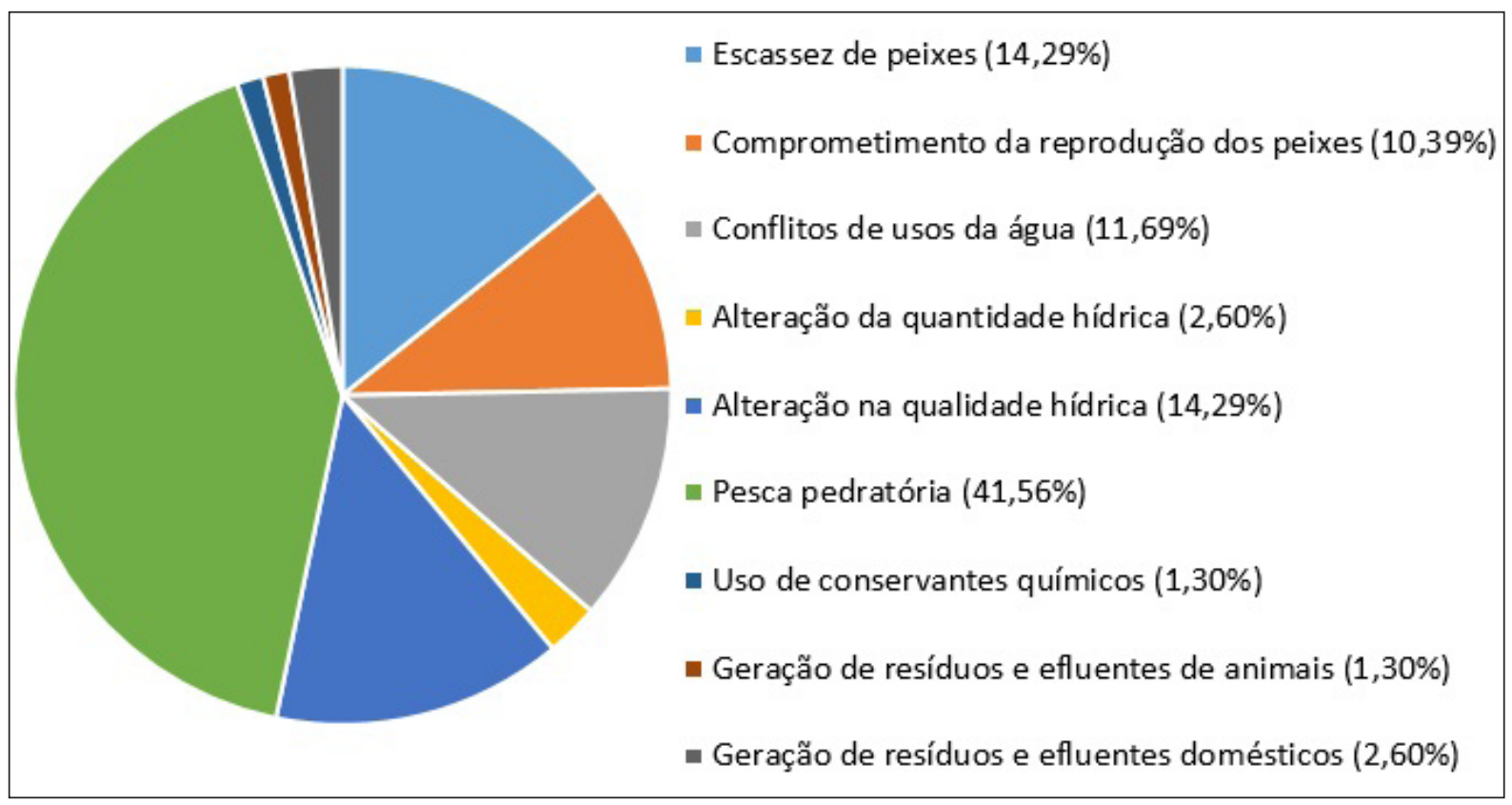

Fonte: Elaborado pelos autores (2020).

A discussão ambiental atual passa por uma compreensão sistêmica e holística, sendo, para Sachs (2002), o caminho para o desenvolvimento sustentável, no tocante às dimensões cultural, 
social, econômica, ecológica, espacial; além disso, é necessário considerar a participação social como proposta para identificar os problemas ambientais e planejar ações a partir da percepção que o homem tem de seu meio, já que pode fornecer aos órgãos dirigentes orientações mais adequadas para as decisões em nível político, socioeconômico e de desenvolvimento (DEL RIO; OLIVEIRA, 1996). Em se tratando do desenvolvimento local, a partir da pesca, Barakagira e Wit (2017) afirmaram que esse requer o envolvimento e a participação ativa de membros da comunidade local.

Investigou-se quais os problemas de maiores urgências a serem solucionados na área de estudo, com predomínio de problemas ambientais (poluição da lagoa, 20,47\%, e falta de esgoto doméstico, 18,90\%); econômico (desemprego, 13,38\%); e social (saúde, 12,60\%, e violência, 9,45\%) (Figura 4). Esse resultado é semelhante ao de Morais (2016), o qual averiguou que a poluição do Rio Apodi-Mossoró também foi a mais citada por pescadores. É compreensível a sensibilidade ambiental dos pescadores, já que a alteração na qualidade desses ambientes afeta suas atividades econômicas, como Mozumder et al. (2018) constataram no fato de que a escassez de pescado em Hilsa, em Bangladesh, tem ocasionado muitas consequências sociais e tornando os pescadores menos resilientes socialmente.

Figura 4 - Problemas mais urgentes na comunidade

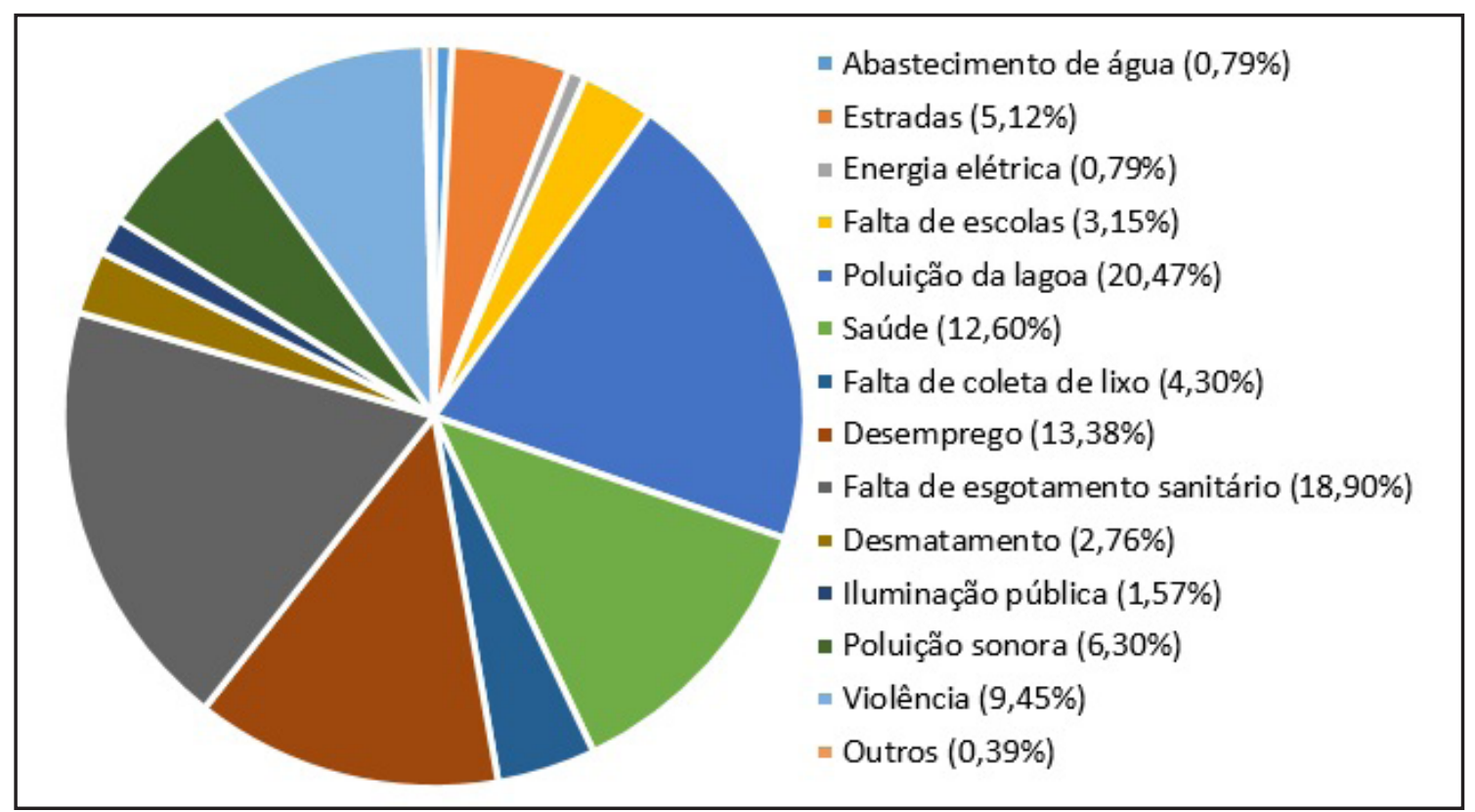

Fonte: Elaborado pelo autor (2018).

O cenário de conflitos ambientais, econômicos e sociais na área de estudo já vem sendo alertado por Pinto Filho e Oliveira (2008), ao desenvolver estudo sobre os impactos socioambientais na Lagoa do Apodi, RN. Para compreender a extensão dessa problemática, indagou-se aos pescadores a percepção dos conflitos existentes atualmente, sendo que 52,83\% não souberam responder. Esse aspecto pode refletir o analfabetismo ambiental, que Reigota (2007) define como uma carência, e não de fato um analfabetismo com relação às concepções e percepções sobre o tema.

Dos conflitos existentes entre a pesca com outros usuários na Lagoa do Apodi, RN, a pesca predatória é citada por $22,65 \%$ dos pescadores, sendo desenvolvida com a utilização da rede 
de arrasto, sem obedecer ao período de defeso das espécies. Outros conflitos também foram observados: 20,75\% apontaram conflitos de terra entre pescadores e agricultores, principalmente no que diz respeito ao manuseio da comporta que regula a quantidade de água na lagoa. $\mathrm{O}$ comprometimento da qualidade hídrica por despejo de esgotos domésticos foi evidenciado por 3,77\% dos pesquisados. Esse cenário de conflitos ocorre devido às ações do homem sobre a natureza gerarem resultados oscilantes e nem sempre agradáveis, o que por sua vez acaba retornando para ele mesmo, intervindo na sua qualidade de vida e nas suas relações com o ambiente no qual está inserido (FONTES; QUEIROZ, 2015). Merece destaque sobre os impactos na atividade pesqueira, ainda, o estudo de Ndhlovu et al. (2017), que constatou alterações na pesca no Lago Kariba, Zimbábue, devido às mudanças climáticas. Nessa perspectiva, os pescadores demonstraram ter conhecimento desses distúrbios por meio das seguintes falas:

"A pesca sem controle dentro da lagoa". (Entrevistado 3, 64 anos).

"Quando não se tem água, os agricultores plantam forragem, mas é para encher a lagoa para poder pescar". (Entrevistado 4, 49 anos).

"A população do bairro jogam o lixo dentro da lagoa". (Entrevistado 5, 58 anos).

"Os comerciantes que jogam o lixo e os esgotos na água da lagoa e prejudica a pesca". (Entrevistado 6, 35 anos).

A partir deste panorama de vulnerabilidade socioeconômica e ambiental na Lagoa do Apodi, RN, deve-se buscar diálogo entre os usuários desse ambiente, sendo respaldado no caput do artigo 225, da Constituição Federal de 1988, que prevê:

Todos têm direito ao meio ambiente ecologicamente equilibrado, bem de uso comum do povo e essencial à sadia qualidade de vida, impondo-se ao Poder Público e à coletividade o dever de defendê-lo e preservá-lo para as presentes e futuras gerações. (BRASIL, 1988).

Nessa compreensão, os pescadores apontaram que a realização da conservação da lagoa, em sua maioria (73,10\%), era realizada pela própria população, seguida do poder público (19,23\%), outros $(5,77 \%)$ e empresas (1,92\%). Ressalta-se ainda que os pescadores mencionaram que o processo de participação se dá com reuniões e mutirões acerca do assunto, sendo desenvolvido com incentivo da colônia de pescadores Z-48.

Portanto as iniciativas de proteção da Lagoa do Apodi, RN, são fundamentais para os pescadores, já que asseguram a manutenção da qualidade ambiental, onde realizam suas atividades para fins de subsistência e comercialização, sendo aprovadas de forma expressiva por todos (88,46\% afirmaram ser muito importantes, e $11,54 \%$, importantes).

\subsection{Práticas usuais e ambientais dos pescadores artesanais}

A compreensão da contextualização ambiental de uma comunidade tradicional ocorre a partir das práticas ambientais que são realizadas em busca de desenvolvimento sustentável (BORGES; ROSA; ENSSLIN, 2010). Sendo assim, faz com que as práticas ambientais dos pescadores da Lagoa do Apodi, RN, sejam investigadas com o propósito de conhecer o quadro atual.

Averiguou-se o conhecimento das técnicas usuais dos pescadores da Lagoa do Apodi, RN, sendo constatado que $50 \%$ dos pescadores utilizam a linha com principal utensílio, 26,39\% utilizam rede e $23,61 \%$ fazem pesca de anzol. Resultados semelhantes foram encontrados por 
Silva (2014), visto que os pescadores do Rio Mumbaba, PB, utilizam com mais frequência os instrumentos de tarrafa e rede ( $23 \%$ da amostra pesquisada). Apesar dos ávanços tecnológicos da pesca, poucas são as mudanças nos métodos e ainda hoje são utilizados equipamentos tradicionais e rudimentares (SANTOS et al., 2011).

A partir desse modelo de pesca, é perceptível que os pescadores investigados utilizam os instrumentos adequados, já que 78,85\% afirmaram nunca utilizarem e 19,23\% responderam quase nunca usarem equipamentos industriais, enquanto apenas 1,92\% usa-os com frequência. Esses resultados foram similares aos de Zappes, Oliveira e Di Beneditto (2016) para pesca no norte fluminense, tendo em vista que raramente usam equipamentos mecanizados. Pode-se inferir que a pesca artesanal, ao fazer uso de utensílios adequados e que não ameaçam a quantidade e as espécies pescadas, adota práticas desenvolvidas por diversas gerações e deixadas como uma herança familiar e cultural pela comunidade, contribuindo, assim, para o desenvolvimento local.

Esse cenário de pesca artesanal na Lagoa do Apodi, RN, consolida-se por 96,15\% afirmarem que fazem uso de canoa, enquanto 3,85\% não usam nenhum tipo de embarcação, o que é corroborado pela descrição da pesca artesanal de Silva (2014), ao afirmar que essa é caracterizada por fazerem pouco uso de tecnologia e embarcações simples. No Maranhão, a pesca também é desenvolvida com pequenas embarcações, já que 51\% utilizam barcos simples e 49\% empregam canoas a remo ou a vela para a execução de suas pescarias (SANTOS et al., 2011). Portanto as principais técnicas adotadas para a captura e a preferência alimentar dos pescadores refletem o destino desses pescados.

Acrescenta-se ainda, para compreensão da pesca artesanal, a frequência como é realizada, visto que há diferença se é para subsistência ou comercialização local e regional. No caso específico dos pescadores da Lagoa, 23,10\% exercem suas atividades entre 1 e 2 dias por semana; 44,20\%, de 3 a 4 dias; 9,6\%, de 5 a 6 dias; e 23,10\%, todos os dias. Valores análogos são apresentados por Silva (2014), já que 65\% dos pescadores do Rio Mumbaba, PB, pescam entre 1 e 2 dias na semana, $23 \%$ pescam entre 3 e 4 dias e $12 \%$ pescam todos os dias. Os aspectos temporários da pesca investigada evidenciam a dependência que a população local tem dos recursos aquáticos para a sua subsistência, sendo necessária, dessa forma, a conservação para atender as gerações futuras; já o desenvolvimento local por meio da pesca ocorrerá quando os pescadores protegerem o ecossistema, participarem do controle dos recursos e impedirem atividades destrutivas.

Ao serem questionados sobre a forma de realização de práticas de proteção ambiental, $75 \%$ afirmaram praticar com muita frequência (respeito à reprodução das espécies e limpeza da lagoa); 9,61\%, com frequência; 7,68\%, regularmente; 3,85\%, quase nunca; e 3,85\%, nunca. Resultados semelhantes foram determinados por Vilches e Ríos (2011) ao investigarem as práticas e os usos dos pescadores da Província de Palena, no Chile. Esse resultado reflete o fato de esses pescadores afirmarem nunca terem sido multados.

Na perspectiva da sustentabilidade da pesca artesanal, investigou-se o respeito dos pescadores para as condições de reprodução na lagoa que, consequentemente, permitam a sucessão ecológica do ecossistema. Com isso, constatou-se que 94,23\% dos entrevistados respeitavam o período de defeso dos peixes, enquanto $5,77 \%$ apontaram que nunca ou quase nunca o respeitam. Essa situação também foi encontrada por pescadores artesanais da colônia Z-55 do município de Mossoró, RN, quanto à poluição do Rio Apodi-Mossoró (MORAIS, 2016). Essa medida permite que não ocorra escassez do pescado e preservem-se as espécies presentes no meio aquático; entretanto precisa ser acompanhada com mais frequência por parte dos órgãos 
competentes. Acauan et al. (2018) sugerem que o período de defeso poderia ser realinhado conforme o conhecimento dos pescadores e pesquisas científicas realizadas na região, lançandose mão da gestão com base participativa, de forma que ocorra uma adequação à realidade, permitindo, assim, o desenvolvimento local.

Para consolidar a viabilidade no futuro da pesca na lagoa, apuraram-se ações necessárias a partir do ponto de vista dos pescadores, sendo mais enfatizados: esgotamento sanitário (46,30\%), limpeza da lagoa (29,64\%), fiscalização da pesca predatória $(11,11 \%)$, retirada das plantações $(5,55 \%)$ e transposição de água para a lagoa (3,70\%). Outros afirmaram não saber (3,70\%). Essas medidas corroboram o pensamento de Jara (2001) e Carvalho e Calhou (2008), ao afirmarem que, por meio da implementação de políticas norteadas pela equidade e satisfação das necessidades humanas, com respeito aos recursos naturais e que permitam o empoderamento dos atores sociais, o estímulo ao capital social e humano instaura o processo de desenvolvimento local. Dessa forma, Allison et al. (2012) mencionaram a participação de pescadores comunitários na gestão da pesca como importante para garantir a subsistência dessa atividade econômica.

Portanto, para assegurar a sustentabilidade ambiental, econômica e social da pesca artesanal na Lagoa do Apodi, RN, faz-se necessária a aplicação de instrumentos da Política Nacional de Meio Ambiente (BRASIL, 1981), tais como: ação governamental na manutenção do equilíbrio ecológico, planejamento e fiscalização do uso dos recursos ambientais, controle e zoneamento das atividades potenciais ou efetivamente poluidoras, recuperação de áreas degradadas, proteção de áreas ameaçadas de degradação e educação ambiental a todos os níveis de ensino, inclusive a educação da comunidade, objetivando capacitá-la para participação ativa na defesa do meio ambiente.

\section{CONSIDERAÇÕES FINAIS}

A Lagoa do Apodi, RN, um importante ecossistema do semiárido brasileiro, vem sendo utilizada para diversos fins, com destaque para: terra de indígenas, área de colonização; atividades agropastoris; pesca; lazer; navegação; e área de expansão urbana para construção de obras, tais como estradas, pontes, postos, residências e calçadão.

Entre esses usos, destaca-se a pesca por uma atividade já consolidada, sendo considerada secular, já que vem sendo desenvolvida em várias décadas e, representando a principal fonte de emprego e renda para diversas famílias que moram no entorno da lagoa, torna-se imprescindível para o desenvolvimento local.

A atividade pesqueira na lagoa é desenvolvida, em sua maioria, por pescadores, com idade de 18 anos até mais de 55 anos, com escolaridade do ensino fundamental incompleto, o que reflete seus rendimentos econômicos mensais de até 1 salário mínimo, já que apresentam a pesca como sua única ocupação; com isso, utilizam o pescado inicialmente como meio de subsistência e, posteriormente, para fins de comercialização.

Diante dessa importância econômica, os pescadores atribuem valores à lagoa, pois essa permite oferecer o alimento, o emprego e a renda. Entretanto os mesmos sujeitos refletem que os múltiplos usos da lagoa ocasionam processos de poluição, principalmente relacionados com atividades urbanas, que resultam em conflitos, como: a pesca predatória; uso e ocupação da lagoa por agricultores e pescadores; a alteração da qualidade hídrica por esgotos domésticos; e destino inadequado de resíduos sólidos. 
A partir da compreensão da complexidade ambiental da pesca artesanal na lagoa em questão, os pescadores passam a entender a necessidade de conservação da lagoa, porém afirmam que ações dessa natureza, em sua maioria, são realizadas apenas pela própria população e, no caso específico deles, as ações restringem-se ao respeito ao período de defeso das espécies aquáticas e ao uso de práticas artesanais, sem uso de instrumentos industriais.

Na perspectiva de contribuição científica, este estudo mostrou-se relevante na medida em que buscou investigar a relação de atividades tradicionais com ambientes aquáticos em uma região do semiárido, porém apresentou desafios relacionados com a mensuração da percepção ambiental, dos conflitos socioeconômicos e ambientais e dos problemas mais recorrentes na área de estudo.

Portanto esta pesquisa permite traçar os caminhos iniciais para a sustentabilidade da pesca na lagoa, que são: reivindicar, do poder público local, assessoria para a manutenção das atividades tradicionais; orientar a fiscalização ambiental dos usos múltiplos na lagoa; articular com o órgão ambiental competente a revisão das atividades potencialmente poluidoras; interceder, junto aos órgãos de recursos hídricos, mediação dos conflitos socioeconômicos e ambientais; estabelecer junto ao órgão ambiental local diretrizes de proteção e recuperação ambiental para o uso e a ocupação das margens da lagoa; e propor ações de educação ambiental não formal para população local.

\section{REFERÊNCIAS}

ACAUAN, Renata Costella; TEIXEIRA, Benjamim; POLETTE, Marcus; BRANCO, Joaquim Olinto. Aspectos legais da pesca artesanal do camarão sete-barbas no município de Penha, SC: o papel do defeso. Interações, Campo Grande, v. 19, n. 3, p. 543-56, 2018.

ALLISON, Edward H.; RATNER, Blake D.; ÅSGÅRD, Björn; WILLMANN, Rolf; POMEROY, Robert; KURIEN, John. Rights-based fisheries governance: from fishing rights to human rights. Fish Fish, v. 13, p. 14-29, 2012.

BABBIE, Earl. Métodos de pesquisas de survey. Belo Horizonte: UFMG, 2001.

BALASSIANO, Moisés; SEABRA, Alexandre Alves; LEMOS, Ana Heloisa. Escolaridade, salários e empregabilidade: tem razão a teoria do capital humano? Revista Administração Contemporânea, v. 9, n. 4, p. 31-52, 2005.

BARAKAGIRA, Alex; WIT, Anton H. de. Community livelihood activities as key determinants for community based conservation of wetlands in Uganda. Environmental \& Socio-economic Studies, v. 5, p. 11-24, 2017.

BRASIL. Lei n. 9.795, de 27 de abril de 1999. Dispõe sobre a educação ambiental, institui a Política Nacional de Educação Ambiental e dá outras providências. Brasília, DF: 1999. Disponível em: http://www.planalto. gov.br/ccivil_03/leis/I9795.htm. Acesso em: 17 jun. 2019.

BRASIL. Constituição da República Federativa do Brasil. Brasília, DF: Senado Federal, 1988. 292 p. Disponível em: http://www.planalto.gov.br/ccivil_03/constituicao/constituicao.htm. Acesso em: 10 jun. 2019.

BRASIL. Lei Federal n. 6.938, de 31 de agosto de 1981. Dispõe sobre a Política Nacional do Meio Ambiente, seus fins e mecanismos de formulação e aplicação. Brasília-DF: Senado Federal, 1981. Disponível em: https:// www2.camara.leg.br/legin/fed/lei/1980-1987/lei-6938-31-agosto-1981-366135-publicacaooriginal-1-pl. html. Acesso em: 10 jun. 2019.

BORGES, Ana Paula; ROSA, Fabrícia Silva; ENSSLIN, Sandra Rolim. Evidenciação voluntária das práticas ambientais: um estudo nas grandes empresas brasileiras de papel e celulose. Produção, v. 20, n. 3, p. 404-17, 2010. 
BOLFARINE, Heleno; BUSSAB, Wilton de Oliveira. Elementos de amostragem. São Paulo: Blucher, 2005.

BOURDIEU, Pierre; PASSERON, Jean-Claude. Escritos de educação. Petrópolis: Vozes, 1998.

CARVALHO, Felipe Eduardo Araújo de; CALLOU, Angelo Brás Fernandes. Extensão pesqueira e desenvolvimento local: a experiência da Secretaria Especial de Aquicultura e Pesca no Estado de Pernambuco, 2003-2006. Interações, Campo Grande, v. 9, n. 1, p. 65-76, 2008.

CUNHA, Elton José; CALLOU, Angelo Brás Fernandes. Políticas públicas e capital social para o desenvolvimento local da pesca e da aquicultura no Vale do Piancó, Paraíba. Interações, Campo Grande, v. 14, n. 2, p. 237-50, 2013.

DEL RIO, Vicente; OLIVEIRA, Lívia (Org.). Percepção ambiental: a experiência brasileira. São Paulo: Studio Nobel; São Carlos, SP: Universidade Federal de São Carlos, 1996.

DERÍSIO, José Carlos. Introdução ao controle da poluição ambiental. 4. ed. São Paulo. Editora: Oficina de Textos, 2012. 224p.

DIEGUES, Antônio Carlos Sant'Ana. A pesca construindo sociedades: leituras em antropologia marítima e pesqueira. São Paulo: Núcleo de Apoio à Pesquisa sobre Populações Humanas e Áreas Úmidas Brasileiras/ USP, 2004.

EMPRESA DE PESQUISA AGROPECUÁRIA DO RIO GRANDE DO NORTE. Lagoa do Apodi. Parnamirim: EMPARN, 2017. Disponível em: www.emparn.rn.gov.br. Acesso em: 10 jun. 2018.

FONTES, Ozana Leite; QUEIROZ, Alexsandra Fernandes. Uso e ocupação do solo nas margens do açude Flechas no município de José da Penha/RN. GEOTemas, Pau dos Ferros, RN, v. 5, n. 1, p. 3-17, 2015.

GIL, Antônio Carlos. Métodos e técnicas de pesquisa social. 6. ed. São Paulo: Atlas, 2008.

HIRATA, Helena Sumiko; KERGOAT, Danièle. La division sexuelle du travail revisitée. In: MARVANI, M. (Org.). Les nouvelles frontiers de l'inegalité. Paris: La decouverte, 1998. p. 93-104.

INSTITUTO BRASILEIRO DO MEIO AMBIENTE. Monitoramento da atividade pesqueira no litoral nordestinoProjeto Estatpesca. Centro de Pesquisa e Gestão de Recursos Pesqueiros do litoral do Nordeste - Cepene. Tamandaré, Brasil: IBAMA, 2008. 384 p.

INSTITUTO BRASILEIRO DE GEOGRAFIA E ESTATÍSTICA. Estimativas da população residente nos municípios brasileiros. IBGE 2016. Disponível em: https://ww2.ibge.gov.br/home/estatistica/populacao/ estimativa2015/estimativa_dou.shtm. Acesso em: 1o jun. 2018.

JARA, Carlos Julio. As dimensões intangiveis do desenvolvimento sustentável. Expo Brasil Desenvolvimento Local. IICA - Brasil. Brasília, 2001. (Colaboração de Maria Verônica Morais Souto).

JESUS, Pablo. Desenvolvimento Local. In: CATTANI, Antonio David (Org.). A outra economia. São Paulo: Veraz Editores, 2003. p. 72-75.

KASHIMOTO, Emília Mariko; MARINHO, Marcelo; RUSSEF, Ivan. Cultura, identidade e desenvolvimento local: conceitos e perspectivas para regiões em desenvolvimento. Interações, Campo Grande, MS, v. 3, n. 4, 2002.

MEIRA, Ana Cláudia Hebling; ALMEIDA, Jalcione. O mito do desenvolvimento no litoral sul do Espírito Santo, Brasil. Interações, Campo Grande, v. 19, n. 2, p. 439-53, 2018. 
MELAZO, Guilherme Coelho. A percepção ambiental e educação ambiental: uma reflexão sobre as relações interpessoais e ambientais no espaço urbano. Olhares \& Trilhas, Uberlândia, Ano 6, n. 6, p. 45-51, 2005.

MINISTÉRIO DA PESCA E AGRICULTURA. Boletim Estatístico da Pesca e Aquicultura. 2010. 128 f. Brasília: Mapa, 2012.

MORAIS, Jefferson Alves. Caracterização higiênico-sanitária e socioambiental da pesca artesanal do Rio Apodi-Mossoró, RN. 2016. Dissertação (Mestrado em Ambiente, Energia e Sociedade) - Universidade Federal Rural do Semi-Árido, Mossoró, RN, 2016.

MOZUMDER, Mohammad Mojibul Hoque; WAHAB, Md. Abdul; SARKKI, Simo; SCHNEIDER, Petra; ISLAM, Mohammad Mahmudul. Enhancing social resilience of the coastal fishing communities: a case study of hilsa (Tenualosa ilisha H.) Fishery in Bangladesh. Sustainability, v. 10, n. 10, p. 3501, 2018.

NDHLOVU, Nobuhle; SAITO, Osamu; DJALANTE, Riyanti; YAGI, Nobuyuki. Assessing the sensitivity of smallscale fishery groups to climate change in Lake Kariba, Zimbabwe. Sustainability, v. 9, n. 12, p. 2209, 2017.

ORGANIZAÇÃO DAS NAÇÕES UNIDAS PARA ALIMENTAÇÃO E A AGRICULTURA. Revisão do marco institucional, da estrutura institucional e organizacional da SEAP/PR. Brasil: FAO, 2006. Disponível em: http://www.fao.org/tempref/docrep/fao/011/ai265p/ai265p00.pdf. Acesso em: 24 jul. 2019.

PINTO FILHO, Jorge Luís de Oliveira; OLIVEIRA, Alan Martins. Impactos socioambientais da ocupação desordenada das margens da lagoa de Apodi. Revista Verde de Agroecologia e Desenvolvimento Sustentável, Mossoró, v. 3, n. 1, p-58-76, 2008.

PINTO FILHO, Jorge Luís de Oliveira; SANTOS, Edna Guilherme; SOUZA, Maria Juliana Jamille Barra. Proposta de índice de qualidade de água para a lagoa do Apodi, RN, Brasil. Holos, Natal, v. 2, n. 28, p. 69-76, abr. 2012.

RAMIRES, Milena; BARRELLA, Walter; ESTEVES, Andréia Martucci. Caracterização da pesca artesanal e o conhecimento pesqueiro local no Vale do Ribeira e Litoral Sul de São Paulo. Revista Ceciliana, v. 4, p. 37-43. 2012.

REIGOTA, Marcos. Meio ambiente e representação social. 7. ed. São Paulo: Cortez, 2007.

ROCHA, Juliana D.; BURSZTYN, Maria Augusta. A importância da participação social na sustentabilidade do desenvolvimento local. Interações, Campo Grande, MS, v. 7, n. 11, p. 45-52, 2005.

SACHS, Ignacy. Caminhos para o desenvolvimento sustentável. 1. ed. Rio de Janeiro: Garamond, 2002.

SÁNCHEZ, Luis. Enrique. Avaliação de impacto ambiental: conceitos e métodos. 2. ed. São Paulo: Oficina de Textos, 2012. 495 p.

SANTOS, Paula Verônica Campos Jorge; ALMEIDA-FUNO, Izabel Cristina da Silva; PIGA, Fabíola Geovanna; FRANÇA, Victor Lamarão; TORRES, Suzana Araujo; MELO, Carla Danielle Paixão. Perfil socioeconômico de pescadores do município da Raposa, estado do Maranhão. Revista Brasileira de Engenharia de Pesca, v. 6, n. 1, 2011.

SEIXAS, Sênia Regina da Cal; HOEFFEL, João Luiz de Moraes; RENK, Michelle; SILVA, Benedita Nazaré; LIMA, Fábio Bueno. Percepção de pescadores e maricultores sobre mudanças ambientais globais, no litoral Norte Paulista, São Paulo, Brasil. Revista de Gestão Costeira Integrada, v. 14, n. 1, p. 51-64, 2014.

SILVA, Ana Elizabeth Dias. Pesca artesanal e condições ambientais: a percepção dos pescadores do Rio Mumbaba, bacia do Rio Gramame, PB. 2014. Dissertação (Mestrado em Desenvolvimento e Meio Ambiente) - Universidade Federal da Paraíba, João Pessoa, PB, 2014. 
SILVA, Anelino Francisco. A pesca artesanal como arte e como significado cultural: o caso Potiguar. Acta Geográfica, v. 4, n. 8, p. 57-65, 2010.

SILVA, Edilma Fernandes; OLIVEIRA, Jorge Eduardo Lins; SCHIAVETTI, Alexandre. Conhecimento ecológico local (CEL) na pesca artesanal da Reserva de Desenvolvimento Sustentável Estadual Ponta do Tubarão RN, Brasil. Boletim do Instituto de Pesca, São Paulo, v. 40, n. 3, p. 355-75, 2014.

SOARES, Lorena Lívina Lima Oliveira; PINTO FILHO, Jorge Luis de Oliveira; FEITOSA, Alex Pinheiro; BEZERRA, Joel Medeiros. Perfil socioeconômico e percepção ambiental dos moradores do entorno da Lagoa do Apodi, Rio Grande do Norte. Revista Verde de Agroecologia e Desenvolvimento Sustentável, v. 14, n. 1, p. 111-9, 2019.

VILCHES, Paula Salinas; RíOS, Francisco Ther. Prácticas y usos del espacio marino a través del tiempo en caletas de pescadores artesanales: el Manzano y Puntilla Pichicolo, Comuna de Hualaihué, Provincia de Palena, Chile. Interações, Campo Grande, MS, v. 12, n. 2, p. 269-89, 2011.

ZACARKIM, Carlos Eduardo; DUTRA, Fabricio Martins; OLIVEIRA, Luciano Caetano. Perfil dos pescadores da foz do rio Araguaia, Brasil. Extensio: Revista Eletrônica de Extensão, Florianópolis, v. 14, n. 25, p. 2744, 2017.

ZAPPES, Camila Antunes; OLIVEIRA, Pablo da Costa; DI BENEDITTO, Ana Paula Madeira. Percepção de pescadores do norte fluminense sobre a viabilidade da pesca artesanal com a implantação de megaempreendimento portuário. Boletim Instituto Pesca, São Paulo, v. 42, n. 1, p. 73-88, 2016.

\section{Sobre os autores:}

Jorge Luís de Oliveira Pinto Filho: Doutor em Desenvolvimento e Meio Ambiente pela Universidade Federal do Rio Grande do Norte (UFRN), com doutorado-sanduíche na Technische Universität Bergakademie Freiberg, Alemanha. Pós-Doutorado no Centro de Estudos de Geografia e Ordenamento do Território (CEGOT) da Universidade de Coimbra (UC) sob orientação de Lúcio Cunha. Professor Adjunto do Departamento de Engenharias e Tecnologia (DETEC), do Centro Multidisciplinar de Pau dos Ferros-(CMPF/UFERSA), e Pesquisador Permanente no Programa de Pós-Graduação em Planejamento e Dinâmicas Territoriais do Semiárido (PLANDITES/UERN). E-mail: jorge.filho@ufersa.edu.br, Orcid: http://orcid.org/0000-0002-2730-6929

Samilly Brito Nobre: Mestranda em Ambiente, Tecnologia e Sociedade Universidade Federal Rural do Semi-Árido (UFERSA). Bacharel em Ciência e Tecnologia pela Ufersa, Centro Multidisciplinar de Pau dos Ferros (CMPF). E-mail: samillybritto2010@hotmail.com, Orcid: http://orcid.org/0000-0001-9915-1818

Manoel Mariano Neto: Doutorando em Engenharia Civil e Ambiental pela Universidade Federal de Campina Grande (UFCG). Mestre em Planejamento e Dinâmicas Territoriais no Semiárido pela Universidade do Estado do Rio Grande do Norte (UERN). Bacharel em Ciência e Tecnologia; e em Engenharia Ambiental e Sanitária pela Universidade Federal Rural do Semi-Árido (UFERSA). E-mail: marianop.paiva2@gmail.com, Orcid: http://orcid.org/0000-0002-3106-1012 
